\title{
MATHEMATICAL MODELING OF TRACTOR MOVEMENT ON THE SLOPE
}

\author{
AZIMOV B.M ${ }^{1}$, SULYUKOVA L. F ${ }^{2}$, AKHMEDOV SH. A ${ }^{3}$, AZIMOV M. B ${ }^{4}$ \\ ${ }^{1,2,4}$ Scientific and Innovation Centre of Information and Communication Technologies under Tashkent IT University, Tashkent, \\ Uzbekistan
}

${ }^{3}$ LLC Design Technological Center of Agricultural Machines (KTCSM), Tashkent, Uzbekistan

\begin{abstract}
Researching issues of the controllability and stability of wheeled tractors on slopes with road irregularities using
mathematical modeling and optimal control are considered in the paper. The static transverse stability at the limiting
angle of the slope is pre-determined. In accordance with the calculation scheme, generalized mathematical models in the
form of Lagrange equations of the second kind for horizontal and vertical oscillations of a four-wheeled tractor in the
process of moving along the road-irregularities on the turning strip of the cotton field are developed. The theory of
optimal systems is used to control the movement of the tractor, control purpose and functional in the form of performance
evaluation are formulated. The Pontryagin maximum principle was used to study the necessary conditions for optimal
control. The conjugate system with variation of design parameters and generalized models under different conditions of
tractor movement are investigated by numerical method. The functioning conditions of the tractor and the main
parameters arising from vibrations of the tractor in obstacle negotiation on the slopes with ensuring of the stabilization.
KEYWORDS: Wheeled Tractor, Modeling, Optimal Control, Numerical Method, Oscillations
\end{abstract}
Received: Jun 10, 2020; Accepted: Jun 30, 2020; Published: Jul 27, 2020; Paper Id.: IJMPERDJUN2020469

\section{INTRODUCTION}

In recent years the analysis of the methods of diagnosing and mathematical simulation of technological machines and systems operation has shown that the relevant studies have been conducted within the framework of a singlelevel structure of research. Such a structure does not provide accurate values of adjusting, damping, stiffness parameters of control and test objects for maintaining transient processes within specified limits due to the absence of interacting subsystems of state and control assessment. The need and relevance of research in this area is proved by the lack of knowledge on the application of multi-level simulation structure and optimal control of dynamic modes in the process of diagnosing the parameters of a four-wheel universal plough tractor [1-6].

\section{MATHEMATICAL MODELING OF TRACTOR MOVEMENT ON THE SLOPE}

When the tractor is moving along the slope and its left and right wheels hit on an obstacle of the height higher than the limit one, it will be affected by an overturning moment leading to unstable equilibrium position (Figure 1). Later, the tractor may overturn on its side around the outer edge of the rear wheel tire as a result of displacement of its center of gravity. As is known, the condition for maintaining the stability of the tractor is achieved by the ratio $[7,8]$ :

$M_{s t b} \geq M_{o t}$,

Where $M_{s t b}$ is the moment of the forces tending to return the tractor to its original position, N.m; $M_{o t}$ is the 
overturning moment, $\mathrm{N} \cdot \mathrm{m}$.

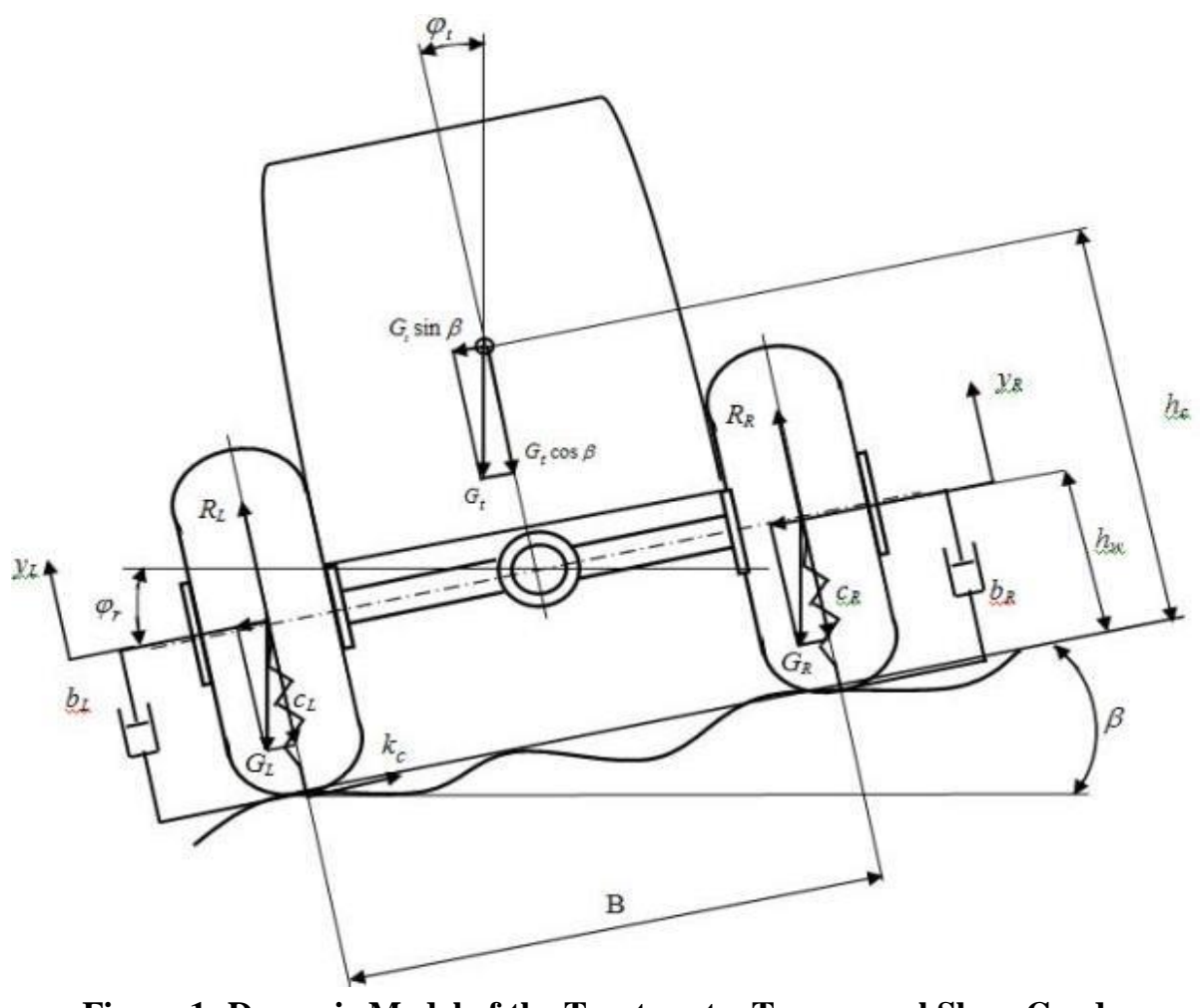

Figure 1: Dynamic Model of the Tractor at a Transversal Slope Grade.

When the wheel is rolling on a slope, the contact spot of the tire with the slope surface under lateral component of the load $G_{z}$ is distorted and takes the form of a curved ellipse [7, 8].

The overturning is preceded by the redistribution of support reactions along the sides. The limiting position arises at the point when a vertical plane passing through the center of mass crosses the overturning axis. Static lateral stability of the tractor is estimated by the limiting angle of the slope when the tractor is stationary.

The reactions of the sides downward $R_{A}$ and $R_{B}$ upward the slope at static state of the tractor on a transverse slope of $\beta$ angle are determined from the equilibrium condition of machine relative to the axis passing through the centers of the contacts of the wheels on one side of the tractor $[7,8]$

$$
R_{A}=\frac{1}{2} G \cos \beta+\frac{h_{c} G}{B} \sin \beta, \quad R_{B}=\frac{1}{2} G \cos \beta-\frac{h_{c} G}{B} \sin \beta,
$$

where $B$ is the tractor gauge, $1.8 \mathrm{~m} ; h_{c}$ is the height of the center of mass of the tractor, $1 \mathrm{~m} ; G=m g$ is the gravity force of the tractor, tractor weight, $m=4750 \mathrm{~kg}$.

Table 1 and Figure 2 show the calculated values of the reaction of the left and right wheels of the tractor.

The load on the side downward the slope increases, and the load on the other side decreases. The redistribution of normal reactions on the sides depends not only on the tractor gauge, but also on the vertical coordinate of the center of mass. The tractor is in a statically critical state when the reaction of the unloaded side becomes zero, i.e. $R_{B}=0$. 
Table 1: Calculated Reaction Value of the Left and Right Wheels of the Tractor

\begin{tabular}{|c|c|c|c|c|c|}
\hline No. & $\begin{array}{c}\text { Angle of } \\
\text { slope }\end{array}$ & $\begin{array}{c}\text { Weight on the left wheel } \\
\text { of machine, } \mathbf{k g}\end{array}$ & $\begin{array}{c}\text { Left side reaction } \\
\boldsymbol{R}_{\boldsymbol{A}}=\boldsymbol{R}_{\boldsymbol{L}}, \mathbf{N}\end{array}$ & $\begin{array}{c}\text { Weight on the right } \\
\text { wheel of machine, kg }\end{array}$ & $\begin{array}{c}\text { Right side } \\
\text { reaction } \boldsymbol{R}_{\boldsymbol{B}}=\boldsymbol{R}_{\boldsymbol{R}}, \mathbf{N}\end{array}$ \\
\hline 1. & $\beta=0$ & $\begin{array}{c}\sin \beta=0 \\
\cos \beta=1\end{array}$ & 2375 & 23298.75 & 2375 \\
\hline 2. & $\beta=10^{\circ}$ & $\begin{array}{l}\sin \beta=0.1736 \\
\cos \beta=0.9848\end{array}$ & 2797.156 & 27440.1 & 1880.683 \\
\hline 3. & $\beta=20^{\circ}$ & $\begin{array}{l}\sin \beta=0.3420 \\
\cos \beta=0.9397\end{array}$ & 3134.32 & 30747.7 & 1329.215 \\
\hline 4 & $\beta=30^{\circ}$ & $\begin{array}{l}\sin \beta=0.5 \\
\cos \beta=0.866\end{array}$ & 3376.25 & 33121.05 & 737.365 \\
\hline
\end{tabular}

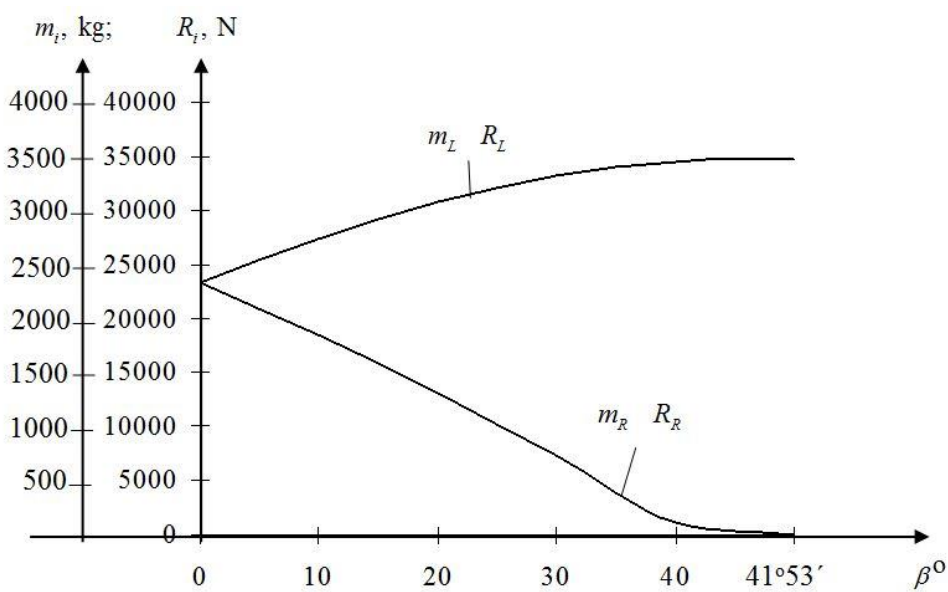

Figure 2: Graph of the Reactions of the Left and Right Wheels of the Tractor.

In accordance with the design scheme given in Figure 1, let's build a generalized mathematical model of horizontal and vertical oscillations of a 4-wheeled tractor in the process of moving over the roughness on the headland of the cotton field in the form of the Lagrange equations of the second kind $[1,2,9,10]$ :

- For Horizontal Oscillations

$$
\left.\begin{array}{rl}
m_{t} \ddot{x}_{t}=F_{x} & -b_{1}\left(\dot{x}_{t}-\dot{x}_{L \rho w}-c_{1}\left(x_{t}-x_{L r w}\right)-b_{2}\left(\dot{x}_{t}-\dot{x}_{R r w}\right)-c_{2}\left(x_{t}-x_{R r w}\right)-\right. \\
& -b_{3}\left(\dot{x}_{t}-\dot{x}_{L f w}\right)-c_{3}\left(x_{t}-x_{L f w}\right)-b_{4}\left(\dot{x}_{t}-\dot{x}_{R f w}\right)-c_{4}\left(x_{t}-x_{R f w}\right) \\
m_{L r w} \ddot{x}_{L r w}= & b_{1}\left(\dot{x}_{t}-\dot{x}_{L r w}\right)+c_{1}\left(x_{t}-x_{L r w}\right)-m_{L r w} \frac{2 \pi^{2} V_{L r w}^{2}}{l_{g r}^{2}} h_{s} \sin \frac{2 \pi V_{L r w}}{l_{g r}} t \\
m_{R r w} \ddot{x}_{R r w}= & b_{2}\left(\dot{x}_{t}-\dot{x}_{R r w}\right)+c_{2}\left(x_{t}-x_{R r w}\right)-m_{R r w} \frac{2 \pi^{2} V_{R r w}^{2}}{l_{g r}^{2}} h_{s} \sin \frac{2 \pi V_{R r w}}{l_{g r}} t \\
m_{L f w} \ddot{x}_{L f w}= & b_{3}\left(\dot{x}_{t}-\dot{x}_{L f w}\right)+c_{3}\left(x_{t}-x_{L f w}\right)-m_{L f w} \frac{2 \pi^{2} V_{L f w}^{2}}{l_{g r}^{2}} h_{s} \sin \frac{2 \pi V_{L f w}}{l_{g r}} t \\
m_{R f w} \ddot{x}_{R f w}= & b_{4}\left(\dot{x}_{t}-\dot{x}_{R f w}\right)+c_{4}\left(x_{t}-x_{R f w}\right)-m_{R f w} \frac{2 \pi^{2} V_{R f w}^{2}}{l_{g r}^{2}} h_{s} \sin \frac{2 \pi V_{R f w}}{l_{g r}} t
\end{array}\right\}
$$


- For Vertical Oscillations

$$
\begin{aligned}
& m_{t} \ddot{y}_{t}=F_{y}-b_{1} \frac{B}{2}\left(\dot{\varphi}_{t}-\dot{\varphi}_{L r w}\right)-c_{1} \frac{B}{2}\left(\varphi_{t}-\varphi_{L r w}\right)-b_{2} \frac{B}{2}\left(\dot{\varphi}_{t}-\dot{\varphi}_{R r w}\right)-c_{2} \frac{B}{2}\left(\varphi_{t}-\varphi_{R r w}\right)- \\
&-b_{3} \frac{B}{2}\left(\dot{\varphi}_{t}-\dot{\varphi}_{L f w}\right)-c_{3} \frac{B}{2}\left(\varphi_{t}-\varphi_{L f w}\right)-b_{4} \frac{B}{2}\left(\dot{\varphi}_{t}-\dot{\varphi}_{R f w}\right)-c_{4} \frac{B}{2}\left(\varphi_{t}-\varphi_{R f w}\right) \\
& m_{L r w} \ddot{y}_{L r w}= b_{1} \frac{B}{2}\left(\dot{\varphi}_{t}-\dot{\varphi}\right)+c_{1} \frac{B}{2}\left(\varphi_{t}-\varphi_{L r w}\right)-m_{L r w} \frac{2 \pi^{2} V_{L r w}^{2}}{l_{g r}^{2}} h_{s}\left(1-\cos \frac{2 \pi V_{L r w}}{l_{g r}} t\right) \\
& m_{R r w} \ddot{y}_{R r w}= b_{2} \frac{B}{2}\left(\dot{\varphi}_{t}-\dot{\varphi}_{R r w}\right)+c_{2} \frac{B}{2}\left(\varphi_{t}-\varphi_{R r w}\right)-m_{R r w} \frac{2 \pi^{2} V_{R r w}^{2}}{l_{g r}^{2}} h_{s}\left(1-\cos \frac{2 \pi V_{R r w}}{l_{g r}} t\right) \\
& m_{L f w} \ddot{y}_{L f w}= b_{3} \frac{B}{2}\left(\dot{\varphi}_{t}-\dot{\varphi}_{L f w}\right)+c_{3} \frac{B}{2}\left(\varphi_{t}-\varphi_{L f w}\right)-m_{L f w} \frac{2 \pi^{2} V_{L f w}^{2}}{l_{g r}^{2}} h_{s}\left(1-\cos \frac{2 \pi V_{L r w}}{l_{g r}} t\right) \\
& m_{R f w} \ddot{y}_{R f w}=b_{4} \frac{B}{2}\left(\dot{\varphi}_{t}-\dot{\varphi}_{R f w}\right)+c_{4} \frac{B}{2}\left(\varphi_{t}-\varphi_{R f w}\right)-m_{R f w} \frac{2 \pi^{2} V_{R f w}^{2}}{l_{g r}^{2}} h_{n}\left(1-\cos \frac{2 \pi V_{R f w}}{l_{g r}} t\right) \\
& j_{t} \ddot{\varphi}_{t}=e m_{L w s} \ddot{y}_{t}-h_{c} k_{c} m_{R w s} \ddot{y}_{t} \sin \frac{2 \pi V_{t}}{l_{g r}} t
\end{aligned}
$$

Where $F_{x}, F_{y}$ - tractor pulling forces; $\dot{x}_{i}, \ddot{x}_{i}, \dot{y}_{i}, \ddot{y}_{i}$ - linear speeds and acceleration of tractor for front and rear wheels of the tractor under horizontal oscillation and vertical oscillations; $\dot{\phi}_{i}, \ddot{\phi}_{i}$ - angular speeds and acceleration of the front and rear wheels of the tractor; $V_{i}$ - tractor speed and its wheels under horizontal and vertical oscillation; $b_{i}, c_{i}-$ coefficients of viscous resistance and rigidity of the wheel tire of a tractor; mi - distributed mass on supports of tractor wheels; $h_{s}$ - height of the road roughness; $l_{g r}$ - distance between the support and road roughness; $e$ - shoulder tire bend, $e=b_{t} / 6 ; b_{t}$-tire width; $h_{c}$ - height of the tractor center of mass; $k_{c}$ - adhesion coefficient of the wheels.

\section{OPTIMAL CONTROL OF TRACTOR MOTION ON A SLOPE}

To solve the problem, the theory of optimal systems is used. The statement of the optimal control problem is as follows.

At the initial time, the test object is in the following state:

$$
q_{i}(0)=q_{0}(0), \quad \dot{q}_{i}(0)=\dot{q}_{0}(0), \quad V_{i}(0)=V_{0}(0)
$$

It is required to choose such a control $u(t)$, which will transfer the test object to a predetermined final state

$$
q_{i}(t)=q_{0}(t), \quad \dot{q}_{\mathrm{i}}(t)=\dot{q}_{0}(t), \quad V_{i}(t)=V_{0}(t) \quad(i=\overline{1, n)}, \quad 0 \leq t \leq T
$$

Time of the transition process should be the shortest. The goal of control is reduced to minimizing the functional $[11,12]$.

$J\left(q_{0}, u(t), q(t)\right)=\int_{t_{0}}^{T} f^{0}(q(t), u(t), t) d t+g^{0}\left(q_{0}, g(T)\right)$

At the conditions equations (2)-(5)

$\dot{q}(t)=f(q(t), u(t), t)$.

Let the functions be set as: 
$g^{i}\left(q_{0}, q(T)\right) \leq 0, \quad \mathrm{i}=1, \ldots, \mathrm{m} ; g^{i}\left(q_{0}, q(T)\right)=0, \quad \mathrm{i}=\mathrm{m}+1, \ldots, \mathrm{s}$

$u \in U, \quad t_{0} \leq t \leq T$,

Where $f(q(t), u(t), t)$ is the continuously differentiable function with its derivatives; $u(t)$ is a piecewise continuous function on the interval $\left[\mathrm{t}_{0}, \mathrm{~T}\right]$.

In machine testing under specified operating conditions, the performance criterion can be an evaluation of the speed of operation.

To study necessary conditions for optimal control, the Pontryagin maximum principle [11, 12] is used.

To formulate the maximum principle $[13,14]$, we introduce the Hamilton - Pontryagin function

$$
H=\left(q, u, t, \psi_{i}, \psi_{0}\right)=-f^{0}(q, u, t)+\langle\psi, u\rangle
$$

And a conjugated system for horizontal oscillations:

$$
\left.\begin{array}{l}
\frac{d \psi_{1}}{d t}=-\frac{\partial H_{t}}{\partial x_{1}}=-m_{t}^{-1}\left(c_{1}+c_{2}+c_{3}+c_{4}\right) \psi_{2}, \\
\frac{d \psi_{2}}{d t}=-\frac{\partial H_{t}}{\partial x_{2}}=-\psi_{1}+m_{t}^{-1}\left(b_{1}+b_{2}+b_{3}+b_{4}\right) \psi_{2} \\
\frac{d \psi_{1}}{d t}=-\frac{\partial H_{L r w}}{\partial x_{3}}=-m_{L r w}{ }^{-1} c_{1} \psi_{2}, \quad \frac{d \psi_{2}}{d t}=-\frac{\partial H_{L r w}}{\partial x_{4}}=-\psi_{1}+m_{L r w}{ }^{-1} b_{1} \psi_{2} \\
\frac{d \psi_{1}}{d t}=-\frac{\partial H_{R r w}}{\partial x_{5}}=-m_{R r w}{ }^{-1} c_{2} \psi_{2}, \quad \frac{d \psi_{2}}{d t}=-\frac{\partial H_{R r w}}{\partial x_{6}}=-\psi_{1}+m_{R r w}{ }^{-1} b_{2} \psi_{2} \\
\frac{d \psi_{1}}{d t}=-\frac{\partial H_{L f w}}{\partial x_{7}}=-m_{L f w}{ }^{-1} c_{3} \psi_{2}, \quad \frac{d \psi_{2}}{d t}=-\frac{\partial H_{L f w}}{\partial x_{8}}=-\psi_{1}+m_{L f w}{ }^{-1} b_{3} \psi_{2} \\
\frac{d \psi_{1}}{d t}=-\frac{\partial H_{R f w}}{\partial x_{9}}=-m_{R f w}{ }^{-1} c_{4} \psi_{2}, \quad \frac{\partial \psi_{2}}{d t}=-\frac{\partial H_{R f w}}{\partial x_{10}}=-\psi_{1}+m_{R f w}{ }^{-1} b_{4} \psi_{2}
\end{array}\right\}
$$

With restriction on control $|u| \leq 1$.

To solve the problem under consideration, the following necessary condition must be met:

$$
H\left(q_{i}(t), u(t), t, \psi_{i}, \psi_{0}\right)=\max _{u \in U} H\left(q_{i}(t), u, t, \psi_{i}(t), \psi_{0}\right)
$$

Proceeding to determining the optimal control of tractor based on (8), the following function for horizontal oscillations is formed as:

$$
\left.\begin{array}{l}
x_{t}=x_{1}, \dot{x}_{t}=x_{2}, \dot{x}_{2}=u_{x}-m_{t}^{-1}\left[b_{1}\left(x_{2}-x_{4}\right)-c_{1}\left(x_{1}-x_{3}\right)-\right. \\
-b_{2}\left(x_{2}-x_{6}\right)-c_{2}\left(x_{1}-x_{5}\right)-b_{3}\left(x_{2}-x_{8}\right)-c_{3}\left(x_{1}-x_{7}\right)- \\
\left.-b_{4}\left(x_{2}-x_{10}\right)-c_{4}\left(x_{1}-x_{9}\right)\right] \\
x_{L r w}=x_{3}, \dot{x}_{L r w}=x_{4}, \dot{x}_{4}=m_{L r w}{ }^{-1}\left[b_{1}\left(x_{2}-x_{4}\right)+c_{1}\left(x_{1}-x_{3}\right)\right]-u_{1} \\
x_{R r w}=x_{5}, \dot{x}_{R r w}=x_{6}, \dot{x}_{6}=m_{R r w}{ }^{-1}\left[b_{2}\left(x_{2}-x_{6}\right)+c_{2}\left(x_{1}-x_{5}\right)\right]-u_{2} \\
x_{L f w}=x_{7}, \dot{x}_{L f w}=x_{8}, \dot{x}_{8}=m_{L f w}^{-1}\left[b_{3}\left(x_{2}-x_{8}\right)+c_{3}\left(x_{1}-x_{7}\right)\right]-u_{3} \\
x_{R f w}=x_{9}, \dot{x}_{R f w}=x_{10}, \dot{x}_{10}=m_{R f w}{ }^{-1}\left[b_{4}\left(x_{2}-x_{10}\right)+c_{4}\left(x_{1}-x_{9}\right)\right]-u_{4}
\end{array}\right\}
$$


If $f^{0} \equiv 1, g^{0} \equiv 0$, then $J\left(q_{0}, u(t), q(t)\right)=T-t_{0}$, in this case the problem presented by equations (4)-(7) is called the problem of operation speed.

The object under consideration is a stationary system and the problem (4) means that $f$ and $U$ do not explicitly depend on time, i.e.

$$
f(t, q, u)=f(q, u), \quad U(t)=U
$$

If the stationary problems (4), (12) have an optimal control $u(t)$ and an optimal path $q_{0}(t)$, then there exists a nonzero vector of conjugate variables $\left(\psi_{1}(t), \quad \psi_{2}(t)\right), \quad \psi(t) \in R^{n}$ satisfying conditions by equation (2), i.e. the maximum condition is satisfied equation (10)

$$
\psi_{0}(t)=\text { const } \leq 0
$$

Since conjugate systems (9) are homogeneous relative to $\psi_{i}$, a constant in equation (13) can be arbitrarily chosen as:

$$
\psi_{0}(t)=-1 \quad 0 \leq \mathrm{t} \leq \mathrm{T}
$$

From the condition $\max _{|u|<1} H$ follows $u=\operatorname{sign} \psi_{2}$ at $\psi_{2} \neq 0$, then the boundary value problem of the maximum principle for horizontal oscillations is written in the following form:

$$
\left.\begin{array}{rl}
\dot{x}_{2}= & \operatorname{sign}_{2}-m_{t}^{-1}\left[b_{1}\left(x_{2}-x_{4}\right)-c_{1}\left(x_{1}-x_{3}\right)-\right. \\
& -b_{2}\left(x_{2}-x_{6}\right)-c_{2}\left(x_{1}-x_{5}\right)-b_{3}\left(x_{2}-x_{8}\right)- \\
& \left.-c_{3}\left(x_{1}-x_{7}\right)-b_{4}\left(x_{2}-x_{10}\right)-c_{4}\left(x_{1}-x_{9}\right)\right] \\
\dot{x}_{4}= & m_{L r w}{ }^{-1}\left[b_{1}\left(x_{2}-x_{4}\right)+c_{1}\left(x_{1}-x_{3}\right)\right]-\operatorname{sign} \psi_{2} \\
\dot{x}_{6}= & m_{R r w}{ }^{-1}\left[b_{2}\left(x_{2}-x_{6}\right)+c_{2}\left(x_{1}-x_{5}\right)\right]-\operatorname{sign} \psi_{2} \\
\dot{x}_{8}= & m_{L f w}{ }^{-1}\left[b_{3}\left(x_{2}-x_{8}\right)+c_{3}\left(x_{1}-x_{7}\right)\right]-\operatorname{sign}_{2} \\
\dot{x}_{10}= & m_{R f w}{ }^{-1}\left[b_{4}\left(x_{2}-x_{10}\right)+c_{4}\left(x_{1}-x_{9}\right)\right]-\operatorname{sign} \psi_{2}
\end{array}\right\} .
$$

The boundary value problem of the maximum principle in this case consists of system equation (15), boundary conditions (2) and (3) resulting from equation (10), and condition (14).

Hamilton-Pontryagin function for horizontal oscillations was composed. Condition (10) will mark out the function $u=\operatorname{sign} \psi_{2}, \psi_{2} \neq 0$. The boundary value problem (15) in this case has the form

$$
H_{i}=-f^{0} u+\psi_{2}(t) u_{t}
$$

Proceed to investigate equation (9), (16) in the area of equation (17)

$$
u_{k}=\operatorname{sign}_{2}(t)=\left\{\begin{array}{ll}
1, & \psi_{2}(t)>1 \\
-1, & \psi_{2}(t)<1
\end{array}, \quad \mathrm{k}=2,4, \ldots, 2 \mathrm{n},\right.
$$

That is, the control $u_{k}(t)$ can have only one switch point [11-14]. 
Thus, from the Pontryagin maximum principle, we obtain the structure of optimal control of motion of the tractor guide wheels.

To determine the auxiliary functions (9), the conjugate system with variation in design parameters $b_{i}, c_{i}, m_{i}$ has been investigated by a numerical method.

As a result, graphical dependences of the rates and accelerations of tractor oscillations, the maximum values of the $\mathrm{H}$-function have been obtained and presented on Figures 3, 4.

\section{RESULTS AND DISCUSSION}

Systems (1a), (1b), (9), (15)) are solved using the Runge-Kutta numerical methods. The control $u_{k}(t)$, bringing the maximum of function (10), is defined in area (18).

Computational experiment has been conducted at the following parameters:

$h_{t}=10 \mathrm{~mm}=0.01 \mathrm{~m}-$ tire deflection; $\quad F_{x}=7500 \mathrm{~N} ; F_{y}=5250 \mathrm{~N} ; c_{l}=\mathrm{c}_{L r w}=1476216.346 \mathrm{~N} / \mathrm{m} ; b_{l}=b_{L r w}=109016.25$ $\mathrm{N} \cdot \mathrm{s} / \mathrm{m} ; \quad c_{2}=c_{R r w}=1474976.96 \mathrm{~N} / \mathrm{m} ; \quad b_{2}=b_{R r w}=108924.727 \mathrm{~N} \cdot \mathrm{s} / \mathrm{m} ; \quad c_{3}=\mathrm{c}_{L f w}=858921.76 \mathrm{~N} / \mathrm{m} ; \quad b_{3}=b_{L f w}=63430.02 \quad \mathrm{~N} \cdot \mathrm{s} / \mathrm{m} ;$ $c_{4}=c_{R f w}=860402.8 \mathrm{~N} / \mathrm{m} ; b_{4}=\mathrm{b}_{R f w}=63539.39 \mathrm{~N} \cdot \mathrm{s} / \mathrm{m} ; m_{l}=4750 \mathrm{~kg} ; m_{L f w}=1760.625 \mathrm{~kg} ; m_{R r w}=1178.8 \mathrm{~kg} ; m_{L f w}=1030.531 \mathrm{~kg}$; $m_{R f w}=692.883 \mathrm{~kg} ; m_{L w s}=2797.156 \mathrm{~kg} ; m_{R w s}=1880.683 \mathrm{~kg} ; r_{r w}=0.785 \mathrm{~m} ; r_{f w}=0.43 \mathrm{~m} ; h_{s}=0.07 \mathrm{~m} ; h_{c}=0.94 \mathrm{~m} ; e=0.0656 \mathrm{~m}$; $k_{c}=0.04 ; b_{t}=0.394 \mathrm{M} ; \beta=10^{0} ; V_{t}=1 \mathrm{~m} / \mathrm{s}$.

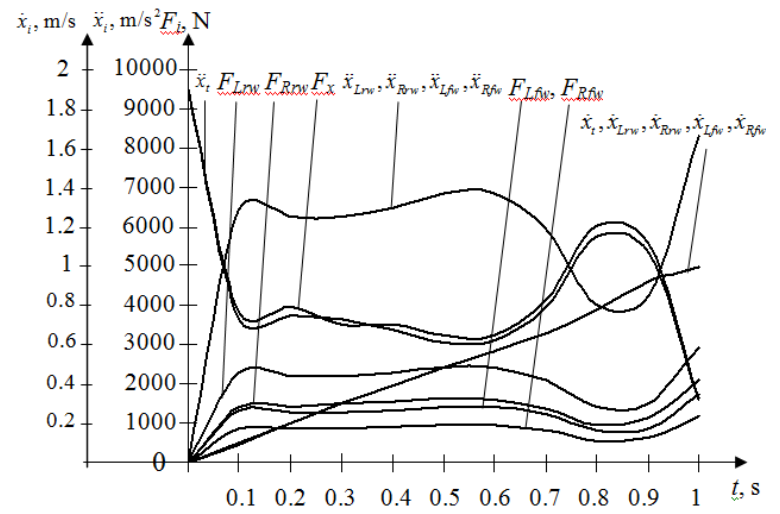

Figure 3: Change Pattern of the Parameters of Motion of a Four-

Wheeled Tractor Under Horizontal Oscillations at $\boldsymbol{h}_{\boldsymbol{t}}=\mathbf{1 0} \mathbf{~ m m}, \beta=10^{0}$.

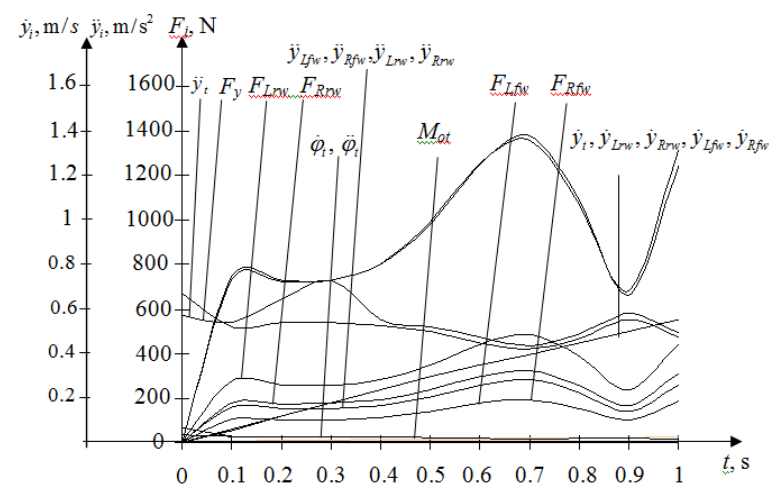

Figure 4: Change Pattern of the Parameters of Motion of a Four-Wheeled Tractor

Under Vertical Oscillations at $\boldsymbol{h}_{t}=\mathbf{1 0} \mathbf{~ m m}, \beta=10^{\circ}$. 


\section{CONCLUSIONS}

- Thus, the smoothness of tractor motion depends on the mass and parameters of the controlled axes, the values of which are determined by numerical solution of the systems (1a), (1b) and the conjugate system (9) with variation in motion parameters $F_{i}$ and design parameters $b_{i}, c_{i}, m_{i}$ for given road roughness.

- The load on the side, located downward the slope, increases, and the load on the other side decreases. The redistribution of normal reactions along the sides depends not only on the machine gauge, but on the vertical coordinate of the center of mass as well. Machine is in a statically critical state when the reaction of the unloaded side is zero, i.e. $R_{B}=0$

- When determining the tractor stability against overturning, the limit angle of the slope is calculated, on which the braking tractor cannot be tipped, and the angle at which the tractor does not slip. The perfection of tractor design when moving down a slope under a load is characterized not only by lateral stability, but by the maximum slope angle of controllability as well.

- To obtain the operating condition of the tractor at different states of equilibrium, it is necessary to determine the principal parameters, such as: driving forces, tractor mass ratio, elastic-dissipative forces and resistance moments arising from tractor oscillations while overcoming the road roughness.

- When taking into account the stability of the tractor in an inclined state, it is necessary to meet the condition of maintaining stability $M_{s t b} \geq M_{o t}$. The limit position occurs at the moment when the vertical plane passing through the center of mass crosses the axis of tipping. The static lateral stability of the tractor is estimated by the limit angle of the slope when the tractor is at rest. The maximum angle of slope is estimated as equal to $\beta=41^{\circ} 53^{\prime}$.

\section{REFERENCES}

1. Azimov, B.M, Akhmedov, Sh.A, Ruzikulov, A.R and Azimov, M.B. (2018). Simulation and optimal control of the movement of a four-wheeled universal-tilled tractor with stepless adjustable clearance. Problems of computational and applied mathematics, 6, 22-35.

2. Azimov, B.M, and Yakubjanova, D.K (2018). Imitation modeling and calculation of the parameters of Lateral forces components of guide wheels of Cotton-picker MH-1.8. International journal of advanced research in science, engineering and technology, 5(1), 5024-32.

3. Ahmetov, A.A., Akhmetov, Sh.A. (2012). Factors affecting agro-technological parameters of the universal-tilling tractors. Vestnik TADI, 1(2), 20-3.

4. Zhou, Z.L., Ding, J.Q., Xu L.Y., Xing M.X., Liu Y.T. (2012). Optimal Control for Tractor Automatic Transmission Shift Process. Advanced Materials Research, Vols. 468-471, 2241-2247. Retrieved from https://www.scientific.net/AMR.468471.2241 .

5. Loghin, Fl., Ene, T.A., Mocanu, V. and Capatîna, I. (2012). Dynamic modeling of technical system tractor - seed drill. Bulletin of the Transilvania University of Brasov. Series II: Forestry Wood Industry • Agricultural Food Engineering, 5 (54), 155 -60.

6. Azimov, B.M., Sulyukova, L.F., Azimov, M.B. (2019). Modeling and Research of the Controllability of Wheeled Tractors. International Journal of Innovative Technology and Exploring Engineering (IJITEE), 9, Issue-1, 2344-2351. 
7. Guskov V.V., Velev N.N., Atamanov Y.E., Bocharov N.F., Ksenevich I.P. and Solonskiy A.S. (1988) Tractors: Theory (Moscow: Mashinostroyenie).

8. Smirnov G.A. (1990). Theory of Motion of Wheel Vehicles (Moscow: Mechanical Engineering).

9. Babashev, K.A. and Azimov B.M. (2018). Mathematical modeling and control of wheel machine testing processes. XVIII conference materials «Informatics: problems, methodology, technologies», 5 (Welborn Voroneg).

10. Macchelli, A., Secchi, C. and Van der Schaft, A. (2013). Lagrangian and Hamiltonian Methods for Modelling and Control. European Journal of Control, 19, 437-530

11. Azimov, B.M. and Yakubjanova, D.K. (2018). Journal of Advanced Research in Dynamical and Control Systems, Special Issue (09), 2513-28

12. Azimov, B.M., Sulyukova, L.F. (2018). Methods for optimal control of grinding processing accuracy on low rigidity shafts. Journal of engineering science and technology, 13(12), 3995-4009.

13. Afanasiev V.N, Kolmanovskii V. and Nosov V.R. (1996). Mathematical Theory of Control Systems Design (Springer Netherlands).

14. Vasiliev F. P. (1988). Numerical methods for solving extreme problems. Moscow: Nauka.

15. Gatea, Ahmed Abed. "Influence of tillage pattern and forward speed of the tractor in the efficiency tillage." International Journal of Agricultural Science and Research (IJASR) 3.4 (2013): 109-120.

16. Khader, MM, NH Sweilam, and M. Adel. "An Approximate Solution for Fractional Optimal Control Problems using Chebyshev Pseudo-Spectral Method." International Journal of Mathematics and Computer Applications Research (IJMCAR) $5.2(2015): 65-76$

17. Akinsola, V. O., and T. O. Oluyo. "A note on the divergence of the numerical solution of the mathematical model for the burden of diabetes and its complications using euler method." International Journal of Mathematics and Computer Applications Research (IJMCAR) 5.3 (2015): 93-100.

18. Anant, Darekar Jyoti, and M. Veerangouda. "Performance Evaluation of Small Tractor-Operated Rotoslasher for Paddy." International Journal of Agricultural Science and Research (IJASR) 10.1 (2020) : 15-22.

\section{AUTHORS PROFILE}

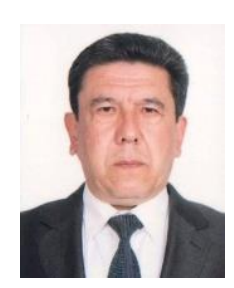

Dr. Azimov Bahtiyor Magrupovich, DSc. in System Analysis, Control and Information Processing (Mechanical Engineering) Profssor and Head of Department "Control in Technical Systems" of Scientific and Innovation Center of Information and Communication Technologies under Tashkent University of Information Technologies (Uzbekistan). Author and co-author of more than 100 scientific papers. 


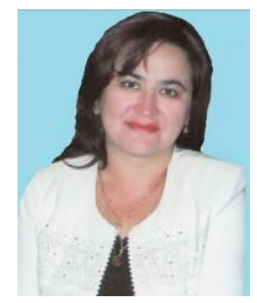

Sulyukova Larisa Faritovna, DSc. in System Analysis, Control and Information Processing (Technical science), Senior Researcher of Department "Control in Technical Systems" of Scientific and Innovation Center of Information and Communication Technologies under Tashkent University of Information Technologies (Uzbekistan). Author and co-author of more than 50 scientific papers. Research interests: Mechanical Engineering, Modeling and Optimal Control of Complex Technological Systems.

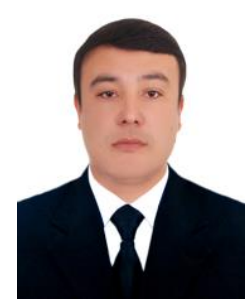

Ahmedov Sherzodbek, Ph. D (Mehanical Engineering) - General Director of LLC Design And Technology Center of Agricultural Machinery. Research interests: modernization of agricultural machinery, increase of agrotechnical passability of universal-tilled tractors, introduction of smart technology in agricultural engineering.

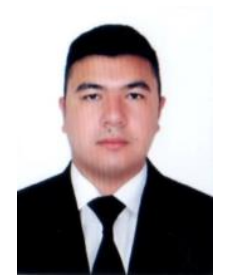

Azimov Mahmud Bahtiyorovich is a research fellow of Scientific and Innovation Center of Information and Communication Technologies under Tashkent University of Information Technologies (Uzbekistan). He has completed his Masters degree in Mechanical Engineering. 